Topics

\title{
Hypervelocity Impacts on Porous Metal: as a Capable Candidate for Debris Bumper Shield Material
}

\author{
By Naomi Onose ${ }^{1)}$, Masumi Higashide ${ }^{1)}$ and Sunao Hasegawa ${ }^{2)}$ \\ ${ }^{1)}$ The Institute of Space and Astronautical Science, JAXA, Sagamihara, Japan \\ ${ }^{2)}$ Aerospace Research and Development Directorate, JAXA, Chofu, Japan
}

(Received June 17th, 2011)

\begin{abstract}
Porous materials absorb impact induced shock well. The pore crushing process results in the compaction of the target, and a considerable part of the impact energy is thought to be consumed in this process. In the case of the impact on gypsum targets, 31 to $62 \%$ of the impact energy was distributed into compaction. In this study, applicability of this effect of compaction to develop lightweight debris bumper shields is considered through impact experiments. Porous aluminum plates were employed as targets and solid aluminum spheres, $1.0 \mathrm{~mm}$ and $0.3 \mathrm{~mm}$ in diameter, were used as projectiles. Normal impacts at about $6 \mathrm{~km} / \mathrm{sec}$ produced bulb shaped craters. Damaged depths in targets were at most $71 \%$ of the ones estimated from impact craterings on solid aluminum plates sharing the same mass per unit area with these porous aluminum plates. Little high speed ejecta was observed by a high-speed video camera.
\end{abstract}

Key Words: Debris Bumper Shield, Impact Experiments, Porous Aluminum

\section{Nomenclature}

$$
\begin{array}{cll}
V & : & \text { velocity } \\
\mathrm{t} & : & \text { thickness } \\
\mathrm{d} & : & \text { diameter } \\
\text { Subscripts } & & \\
\mathrm{p} & : & \text { projectile } \\
\mathrm{t} & : & \text { target }
\end{array}
$$

\section{Introduction}

Since the former Soviet Union successfully launched Sputnik, the world's first artificial satellite, in 1957, the amount of space debris has been growing. Steady augmentation of space debris population creates an increasingly hostile environment for spacecraft in most orbits around the Earth. Nowadays, 16000 objects larger than $10 \mathrm{~cm}$ are cataloged in low earth orbit, and they are still increasing at a rapid rate.

With increasing the number of space debris, the probability of space debris impacts on spacecraft increases. Typical debris impacts are thought to occur at a velocity of around $10 \mathrm{~km} / \mathrm{s}$. Hypervelocity impact will cause extreme damage to the spacecraft's subsystems. In some cases, it may damage flight-critical systems, which can in turn lead to catastrophic failure of the spacecraft ${ }^{1)}$. Although debris larger than $10 \mathrm{~cm}$ in diameter is detected by ground based radars and optical observations, it is impossible to detect debris smaller than 10 $\mathrm{cm}$ by these ways.

The use of a shield can significantly decrease the probability of a catastrophic failure. For example, the Whipple Shield was the first configuration developed to protect spacecraft against meteoroids and orbital debris ${ }^{2}$. However, a more light weight debris shield is also required for unmanned spacecraft.

Porous materials absorb impact induced shock waves well ${ }^{3,4)}$. Pore crushing is an important process during the hypervelocity impact cratering on porous targets. This process results in the compaction of the target. At the same time, the isentropic shock and non-isentropic release process convert the absorbed impact energy into heat. Impact cratering experiments on porous gypsum targets indicated that 28 to $56 \%$ of the impact energy was estimated to consumed by compaction of targets ${ }^{5)}$. In these years, some kinds of porous metals are tested as candidates of light weight debris shields ${ }^{6,7)}$.

In this study, hypervelocity impact experiments on porous aluminum targets were produced, and the impact characteristics of porous aluminum were examined. Depths of craters were compared with the ballistic limit of a solid aluminum plate, which had the same surface density. A high-speed video camera was employed to check whether a high-speed debris cloud was present.

\section{Experimental Procedure}

Hypervelocity normal impact experiments were performed with a two-stage light gas gun at the Institute of Space and Astronautical Science, JAXA.

Porous aluminum plates named Aluminum Foam made by Mitsubishi Materials Corporation were used. A porosity, a nominal diameter of pores, and a thickness of each plate are $82 \%, 300 \mu \mathrm{m}$, and $2 \mathrm{~mm}$, respectively. Figure 1 indicates macroscopic and microscopic pictures of obverse and reverse surfaces of a plate. The obverse of the plate is defined as a 
smooth surface, which indicates less and small holes. In contrast, the reverse of the plate is covered with pores of various sizes. This difference comes from a manufacturing method. Micrographs of surfaces show that aluminum particles, tens of micron in diameter, construct a network with open-pores, $300 \mu \mathrm{m}$ in maximum.
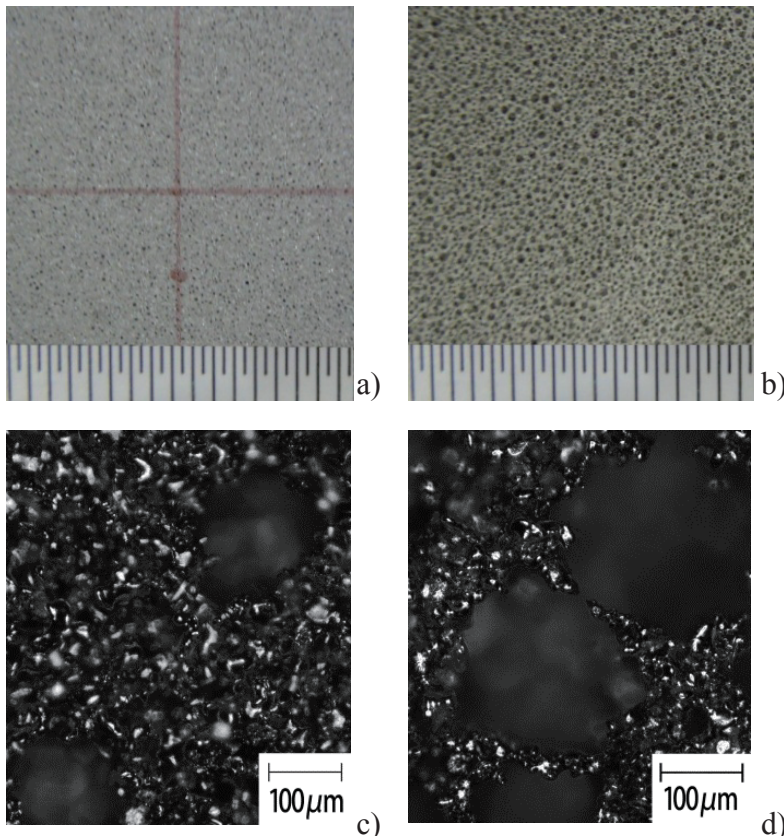

Fig. 1. Surface of a porous aluminum plate. Obverse was defined as more smooth surface of the plate. a) Obverse in macroscopic view. b) Reverse in macroscopic view. c) Obverse in microscopic view. d) Reverse in microscopic view.

The porous aluminum plates are stacked in order to obtain cratering data. In preparation for these experiments, we assumed that the ballistic limits of the porous aluminum were almost the same as those of solid aluminum plates' sharing the same mass per unit area. Some more plates were added to prevent projectiles from penetrating through the target. Ballistic limits for solid aluminum plates under our impact conditions were calculated from the ballistic limit curves ${ }^{8)}$. The stacked plates of porous aluminum were secured with tape, and set in an evacuated chamber as shown in Fig. 2.

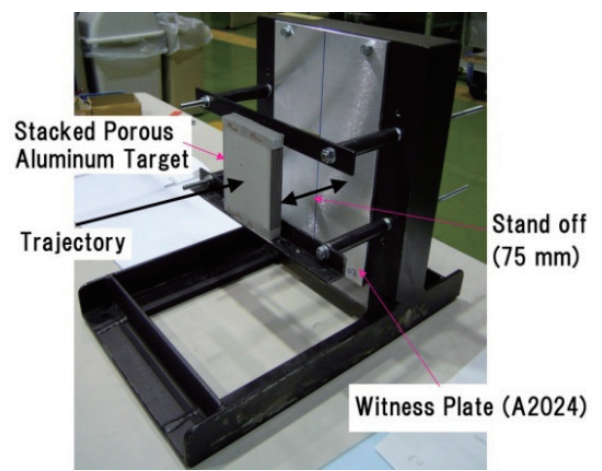

Fig. 2. Setting of the stack of porous aluminum plates. Although there was a witness plate, no visible damage was observed on the rear side of the target.
Aluminum spheres, $1.0 \mathrm{~mm}$ and $0.3 \mathrm{~mm}$ in diameter, were used as projectiles. In this experiments, we set the impact velocity about $6 \mathrm{~km} / \mathrm{sec}$. Although the average impact velocity on the low earth orbit is about $10 \mathrm{~km} / \mathrm{sec}$, it is very difficult to accelerate a projectile to $10 \mathrm{~km} / \mathrm{sec}$. Projectiles were set in a pair of sabot made from polycarbonate. In the case of a projectile, $1.0 \mathrm{~mm}$ in diameter, one projectile was set in each sabot. For projectiles, $0.3 \mathrm{~mm}$ in diameter, a few tens of projectiles were set in one sabot, and they were scattered on the way to the target. Eventually, 18 projectiles hit on the target. The test conditions are shown in Table 1.

\begin{tabular}{|c|c|c|c|c|}
\hline \multicolumn{2}{|r|}{ Shot No. } & 01 & 02 & 03 \\
\hline \multirow[t]{3}{*}{ Projectile } & Material & \multicolumn{3}{|c|}{ Al5056 } \\
\hline & Diameter, $\mathrm{d}_{\mathrm{p}}[\mathrm{mm}]$ & 1.0 & 1.0 & 0.3 \\
\hline & Number & 1 & 1 & 18 \\
\hline \multirow[t]{2}{*}{ Target } & Material & \multicolumn{3}{|c|}{$\begin{array}{l}\text { Porous Aluminum } \\
\text { (Aluminum Foam) }\end{array}$} \\
\hline & Thickness, $\mathrm{t}_{\mathrm{t}}[\mathrm{mm}]$ & 22.5 & 14.2 & 6.1 \\
\hline \multicolumn{2}{|c|}{ Impact Velocity, $\mathrm{V}_{\mathrm{p}}[\mathrm{km} / \mathrm{sec}]$} & 6.07 & 6.08 & 5.93 \\
\hline
\end{tabular}

Optical events were monitored by a high-speed video camera (Hyper Vision HPV-1, Shimadzu Corporation) with a recording speed of 500,000 fps and a spatial resolution of 312 $\times 260$ pixels. One hundred frames can be recorded.

\section{Results}

\subsection{Crater dimensions}

After the impacts, perforated holes were generated on the first plates of porous aluminum. There are no visible damages, such as holes, cracks, and spalls, on the rear-side of all stacked
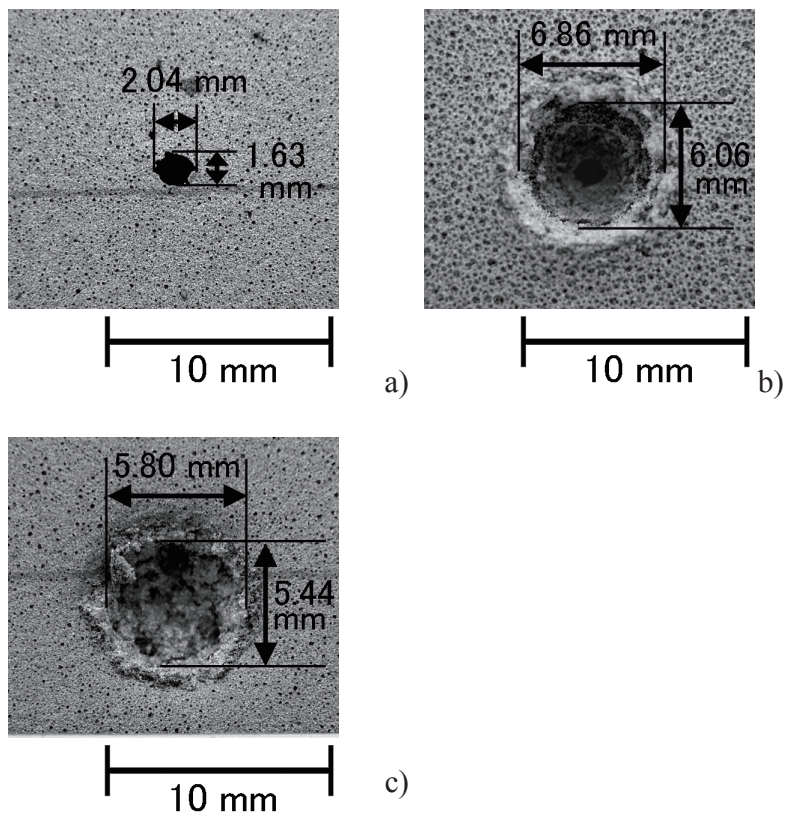

c)

Fig. 3. A Crater made by an impact Shot No. 01 a) Front surface of the stacked target. b) Reverse side of the second layer of the target, $4 \mathrm{~mm}$ in depth. In direction toward the entrance of the crater. c) Obverse side of the third layer of the target. In direction toward the floor of the crater. 
targets. Figure 3 shows overviews of a crater made by the Shot No. 01.

A radius of an entrance hole on this target's surface is about 1.5 times larger than that of projectile's. Internal layers of the target show a cavity having a diameter 5 to 7 times wider than that of the projectile's. This type of crater is called the bulb crater ${ }^{9)}$.

Targets were scanned and diameters of entrance holes were measured by use of ImageJ, provided by National Institute of Health. Depths of craters were measured by a microscope (Keyence Corporation). Depths and diameters of entrance holes of all craters are shown in Fig. 4. Ballistic limits, which is calculated from those of solid aluminum plates, which is sharing the same mass per unit area, are also shown for comparison. These experiments reveal that porous aluminum can protect simulated debris particles at about $70 \%$ of the ballistic limit of the solid aluminum plate, which is sharing the same mass per unit area, though the relationship between the ballistic limits and the crater depths should be discussed.

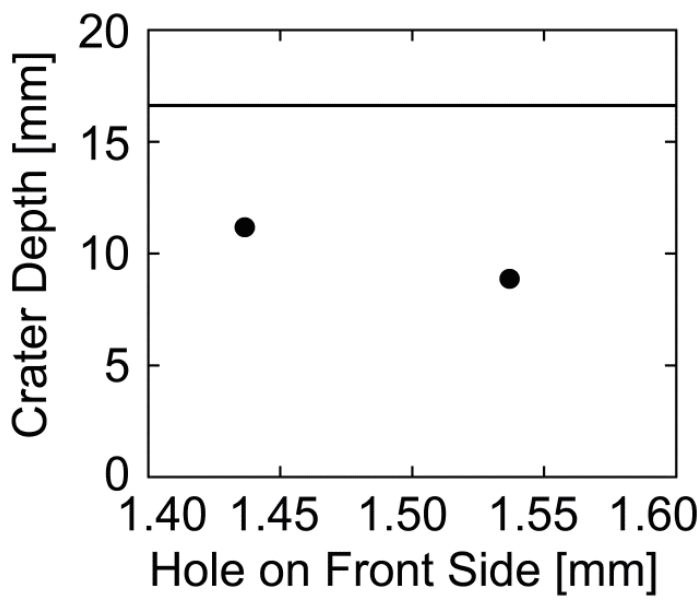

a)

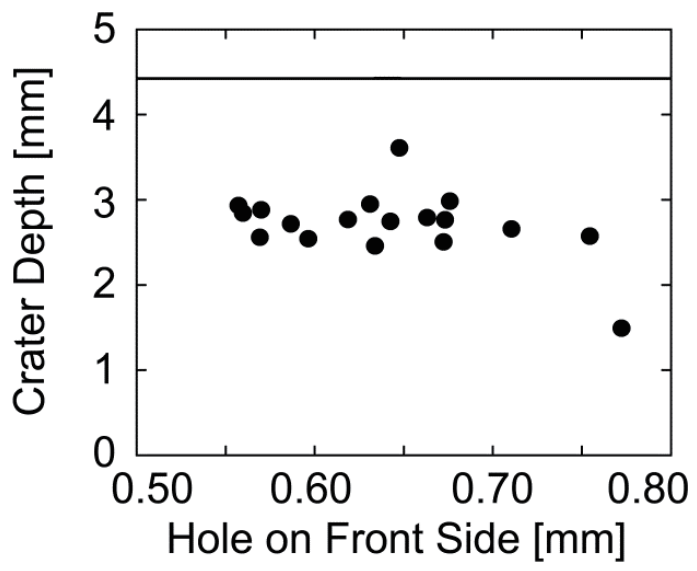

b)

Fig. 4. Depths and Diameters of all craters made on porous aluminum targets. Note that diameters of entrance holes are about one fifth of that of cavities, which are created inside of the target. Ballistic limits estimated from the ones of non-porous targets sharing the same mass per unit area are also indicated for comparison.

\subsection{Optical measurements}

In-situ observation was done for the shot No. 01 with the high-speed video camera. Figure 5 shows a sequence of pictures just before and after the impact. In this experiment, no high-speed debris cloud was observed until $290 \mu \mathrm{sec}$ after the impact.

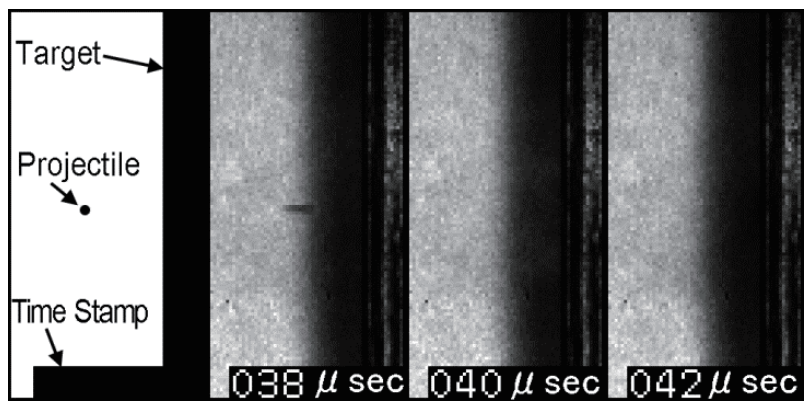

Fig. 5. Pictures just before and after the impact of shot No 01, taken by the high-speed video camera. In the second frame, the projectile, $1 \mathrm{~mm}$ in diameter, is elongated from the limit in exposure time in this condition. Dark areas on the left side of the target were shadows.

\subsection{Deformation of the targets}

Sizes and aspect ratios of each pore on the reverse side of the first layer of each stack of target were measured, for the shots employing projectiles, $1.0 \mathrm{~mm}$ in diameter. Figure 6 shows a scanned image of the reverse surface of the target shot No. 01 at $1200 \mathrm{dpi}$. The first plates were selected because we could observe in-plane deformations of the targets clearly. Target plates in the deeper layers suffered antiplane deformations in the direction of the projectiles' trajectories, in addition to in-plane deformations.

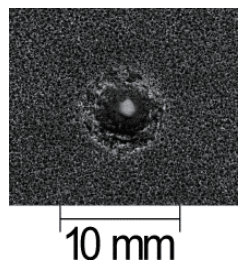

Fig. 6. Scanned image of the reverse surface of the first target shot No. 01 at $1200 \mathrm{dpi}$. White spot at the center of this image is the entrance hole of the crater.

Scanned images of targets were analyzed with ImageJ. Dark spots smaller than 10 pixels were ruled out, because they were too small to compare with the nominal pore size, $0.3 \mathrm{~mm}$ in diameter, and 170 pixels in area. Particles, whose perimeter / diameter ratios were larger than 5, were also ruled out, because they were suspected to be clusters of holes connected with each other.

Particle data was sorted by their distance from the center of the entrance hole, and particle data with its distance from 3.4 $\mathrm{mm}$ to $5 \mathrm{~mm}$ was farther analyzed. Crater walls are located at about $3 \mathrm{~mm}$ from the center in this cross-section. Porous aluminum targets are heavily crushed at the wall of the crater. Target pores, which keep their original shapes, are not observed in these regions, about $1 \mathrm{~mm}$ in width. In contrast, 
pores of the target plates are not damaged in the regions farther than $5 \mathrm{~mm}$ from the center.

In Fig. 7, moving averages of the pore radii and the aspect ratios of the pores are indicated. Each data point represents the mean plus/minus one standard deviation for 60 number of pores. Numbers of pore data were 350 and 400 . Data sets of the pores lie farther than $5 \mathrm{~mm}$ from the center were averaged all together to calculate the radii and the aspect ratios of pores on the initial target. This averaged data for targets before deformations is plotted at $5 \mathrm{~mm}$ in $\mathrm{x}$-axis.

\section{Shot No. 01 \\ Shot No. 02}

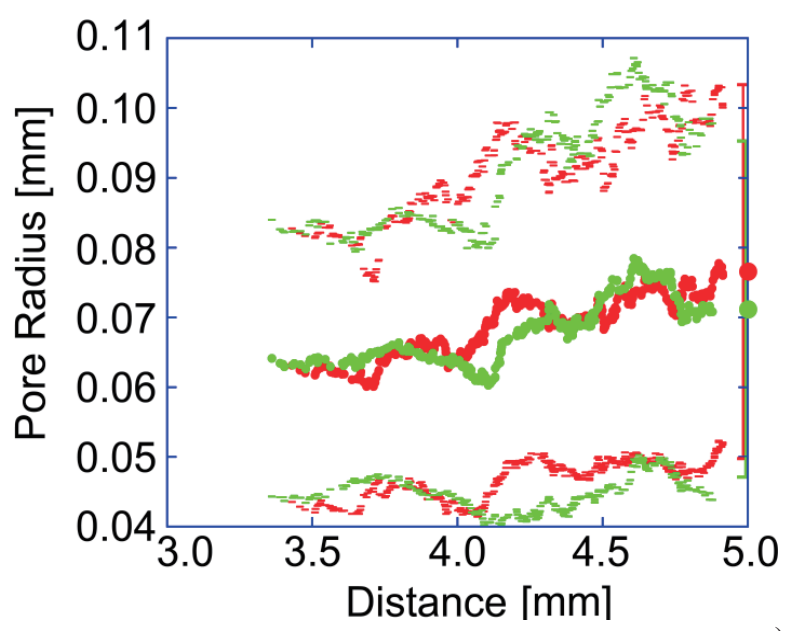

a)

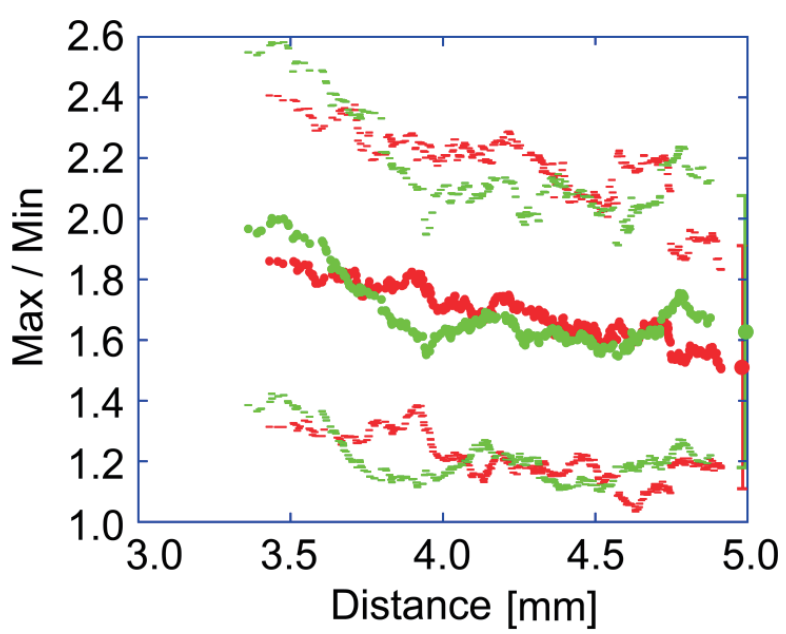

b)

Fig. 7. Sizes and aspect ratio of each pore on the reverse side of the first layers of targets. Each data point represents the mean plus/minus one standard deviation for 60 number of pores. The averaged data for the far regions are plotted at $5 \mathrm{~mm}$ in $\mathrm{x}$-axis. a) Change in pore radius, b) Change in aspect ratio of pores.

Pore radii are decreasing, and aspect ratios are increasing with the distance from the center decreases, although the scatterings of data are large. Together with a deformation of the more seriously damaged area located nearer to the center, deformation of the porous target plays an important role in shock absorption, as proposed in the cases of impacts on gypsum targets ${ }^{5)}$.

\section{Summary}

Normal impact cratering experiments at about $6 \mathrm{~km} / \mathrm{sec}$ were produced on porous aluminum, $82 \%$ in porosity, with open-pores, $300 \mu \mathrm{m}$ in maximum diameter. Solid aluminum projectiles, 1.0 and $0.3 \mathrm{~mm}$ in diameter, were employed. Resulting craters were bulb shaped ones, which had small entrance holes on the obverse surfaces of the targets, and which had large cavities inside of the targets. Depths of these craters are about $70 \%$ of the estimated ballistic limits. No ejection of debris cloud was observed with a high-speed video camera. On the surfaces of the target plates, deformation of the initial existing pores were observed in the narrow regions just next to the crater walls. From these experiments, we propose that porous aluminum is one of the promising candidate of the light weight space debris bumper shield.

\section{Acknowledgments}

The experiments are conducted and supported by the Space Plasma Laboratory, ISAS, JAXA. We thank it's operators Dr. Tabata and Mr. Tsurui for their cooperation. We thank editors and reviewers for their suggestions.

\section{References}

1) Christiansen, E. L.: Meteoroid/Debris Shielding. NASA TP-2003-210788, (2003).

2) Whipple, F. L.: Meteorites and space travel, Astronomical Journal, 52 (1947), pp. 132-137.

3) Resnyansky A. D. and Bourne N. K.: Shock-wave compression of a porous material, J. Appl. Phys., 95 (2004), pp. 1760-1769.

4) Shen A. H., Ahrens T. J. and O'Keefe J. D.: Shock wave induced vaporization of porous solids, J. Appl. Phys., 93 (2003), pp. 5167-5174.

5) Onose, N., Okudaira, K. and Hasegawa, S.: Energy Partition into Compaction of a Target in Impact Cratering in a Gypsum Target, Proceedings of the 40th ISAS Lunar and Planetary Symposium, 2008, pp. 13-22.

6) Ryan, S., Christiansen, E. L. and Lear, D. M.: Shielding Against Micrometeoroid and Orbital Debris Impact with Metallic Foams, Orbital Debris Quarterly News, 14 (2010), pp. 4-6.

7) Jia, B., Li, F., Gong, H. P., and Pang, B. J.: Experimental Comparison of Al Sphere Hypervelocity Impact on Al-Foam Sandwiched Shield and Al-Foam Stuffed Shield, Proceedings of the 61st International Astronautical Congress, 2010, IAC-10-A6.3.6

8) Christiansen, E.L.: Meteoroid/Debris Shielding, NASA Technical Publication 210788 (2003).

9) Stephan, T.: Assessing the elemental composition of comet $81 \mathrm{P} /$ Wild 2 by analyzing dust collected by Stardust, Space Science Reviews, 138, No. 1-4 (2008), pp. 247-258. 